\title{
Anorexia, undernutrition, weight loss, sarcopenia, and cachexia of aging
}

\author{
Ruirui Hao • Hong Guo
}

Received: 26 July 2011 / Accepted: 1 June 2012 / Published online: 17 June 2012

(C) European Group for Research into Elderly and Physical Activity (EGREPA) 2012

\begin{abstract}
During the period between 2000 and 2030, the number of persons older than 65 years is projected to grow from 550 to 937 million worldwide. Globally, this growth represents an increase from 6.9 to $12 \%$. Studies have found that $74.6 \%$ of women and $67.4 \%$ of men aged 65 years or older suffer from many clinical and subclinical syndromes and problems, including anorexia, undernutrition, weight loss, sarcopenia, and cachexia, which are often overlooked or managed inadequately. These issues are very common in the elder. The key clinical question is whether these changes in the elder are distinct entities or an interdependent continuum. In this article, we reviewed these issues of related basic, clinical knowledge. The purpose of this review is to enhance the recognition of anorexia, undernutrition, weight loss, sarcopenia, and cachexia.
\end{abstract}

Keywords Anorexia $\cdot$ Undernutrition · Weight loss · Sarcopenia $\cdot$ Cachexia $\cdot$ Aging

In contrast to 1900 , when life expectancy in industrialized countries of the time was 45-50 years, life expectancy at birth for the world as a whole rose to 65 years at the beginning of the twenty-first century. This gain in longevity is even greater for developed nations, several of which attained life expectancy of over 80 years [74]. This demographic change is expected to have profound implications to health care policy [11]. Elderly individuals are not only going to continue increasing in number, but they will also

R. Hao $\cdot$ H. Guo $(\triangle)$

Medical Healthcare Center of Beijing Friendship Hospital,

Capital Medical University,

95 YongAn Road, XuanWu District,

Beijing 100050, China

e-mail: ccmucpmu@gmail.com comprise a progressively larger proportion of the total population. During the period between 2000 and 2030, the number of persons older than 65 years is projected to grow from 550 to 937 million worldwide. Globally, this growth represents an increase from 6.9 to $12 \%$ [11]. The increased spending to care for the elderly is anticipated to impose a severe stress on existing medical, public health, and social service systems. Prevalence of chronic diseases is high in older individuals and appears to be increasing over recent decades. Weiss et al. found that $74.6 \%$ of women and $67.4 \%$ of men aged 65 years or older suffer from many clinical and subclinical syndromes and problems [89]. These people suffer from many clinical and subclinical syndromes and problems, including anorexia, undernutrition, weight loss, sarcopenia, and cachexia, which are often overlooked or managed inadequately. These issues are very common in the elder. In this article, we reviewed these issues of related basic, clinical knowledge. The purpose of this review is to enhance the recognition of anorexia, undernutrition, weight loss, sarcopenia, and cachexia.

\section{Definition of aging}

Aging has been defined as the loss of entropy and of fractality and as the loss of homeostasis [86]. Entropy is the degree of disorder of a system and reflects the ability of the system to produce energy. Decreased energy production capacity entails a progressive decline in a person's ability to function independently and to cope with stress. A fractal is a unit subdividing into subunits of the same type but whose number and length are unpredictable, similar to the branch of a tree $[3,29]$. Both structural and dynamic fractals maintain the function of the human body. Structural fractals include the circulatory, respiratory, and nervous systems. Cellular renewal is an example of 
a dynamic fractal: a few pluripotent stem cells give origin to progressively more numerous cellular offspring with different degrees of differentiation and maturation. The mechanisms by which the loss of entropy and fractality occurs involve cellular, stromal, and systemic damages. Neither entropy nor fractality can be assessed by clinical means. Homeostasis is the self-regulatory ability of a system, that is the ability to come back to basic conditions after stress. A number of parameters become dysregulated with aging, including blood pressure, circulating concentration of blood sugar, cortisol, and catecholamine. The so-called "allostatic load" assesses the dysregulation of 12 different parameters and is a useful research tool being used for estimating the physiologic age of a person $[3,29]$. Aging is associated with increased concentration of circulating inflammatory markers, including inflammatory cytokines and fibrinolytic products. The concentration of some of these substances is associated with increased risk of death, functional dependence, and geriatric syndromes and may mirror the functional age of the person $[16,38]$. Cure and prolongation of survival are common goals at any age. In the case of the older person, one should add "prolongation of active life expectancy" among the main therapeutic goals. That means prolongation of the time during which the person is independent and able to freely pursue his or her vital interests (advanced activities of daily living) [34].

\section{Aging of gastrointestinal tract}

Aging of the gastrointestinal tract is less obvious than seen in other organs, such as the brain. Most of the changes that occur are of small magnitude and are rarely noticed unless an excessive stress is placed on the gut. The major exception to this seems to be the physiologic anorexia of aging that plays a major role in weight loss with aging and makes older persons highly vulnerable to developing cachexia [48]. It is often difficult to distinguish true physiologic changes that occur with aging and subclinical disease processes as is illustrated in discussing the changes in swallowing and the increased propensity to develop aspiration pneumonia as we age. Another example of this physiology-disease interface is postprandial hypotension [43].

\section{Anorexia of aging}

The concept of a physiologic anorexia of aging was first enunciated clearly in 1988 , although it had been recognized many years ago $[42,47]$. This anorexia is more marked in men than in women. There is an age-related decline in appetite and energy intake in healthy, ambulant, noninstitutionalized people. Healthy older persons are less hungry and more full before a meal, become more rapidly satiated after eating, and eat fewer snacks between meals than younger persons [13]. Average daily energy intake decreases by approximately $30 \%$ between 20 and 80 years of age [92]. Similar study demonstrated older people reductions in energy intake of 19 to $72 \mathrm{kcal} /$ day/year in women and 25 to $100 \mathrm{kcal} /$ day/year in men, respectively, over 6 to 7 years [35]. This physiologic anorexia involves multiple small changes, such as those in taste and smell; altered fundal compliance; altered secretion of gastrointestinal hormones; alterations in autonomic nervous system feedback to the central nervous system; alterations in the fat hormone leptin and in steroid hormones; and changes in the central nervous system in response to food intake [42].

The physiologic reduction in appetite and energy intake has been termed "the anorexia of aging." The causes are not fully understood, probably multiple, and have been reviewed elsewhere. Likely, causes include increased activity of satiety hormones, such as cholecystokinin; diminished activity of hormones stimulating appetite, such as opioids; reduced sense of smell and hence taste and enjoyment of food; and changes in the gastrointestinal system that increase fullness and satiety.

Much of the human experience of taste actually is due to the sensations produced by food in the mouth stimulating the retronasal olfactory receptors. With aging, there is a marked deterioration of olfactory function beginning in the fifth decade [8]. By the age of 80 years, most individuals have less smell identification ability than 5 to 9 years old. Whether these changes are caused by environmental insults, repeated viral infections, or neurodegenerative pathology is uncertain. The four primary tastes (salt, bitter, sweet, and sour) will decrease with aging [88]. Also, older persons lose the increased sensitivity of the tongue tip that is seen in younger persons [39]. Other factors, such as smoking, medications, xerostomia, and local inflammatory conditions can interfere with taste acuity. Severe zinc deficiency can lead to loss of taste acuity. The exact effect of chemosensory dysfunction in the physiologic anorexia with aging is unknown, but it seems to be unimportant [63]. Satiation is related to food stretching the antrum of the stomach [43]. With aging, the adaptive compliance of the fundus of the stomach declines, maybe caused by decrease in nitric oxide production in response to food. This leads to a more rapid escape of food from fundus into antrum. Antral stretch occurs earlier, resulting in early satiation [46, 58]. With aging in humans, there is an increased release of cholecyctokinin (CCK), basally and in response to fat. CCK is a more potent inhibitor of feeding in older persons and animals [37]. Leptin levels increase with aging in men because of the decline in testosterone [65]. It has been suggested that this effect of testosterone on leptin is the reason for the increased anorexia that occurs in aging men compared with women [90]. Many of the orexigenic neuropeptides, which decline with aging, may play an important role in the anorexia with aging $[55,57,68,80]$. It is widely known that anorexia with aging 
makes the old people at major risk for having severe decreases in food intake [7, 51, 87].

\section{Undernutrition of aging}

Diagnosis methods of undernutrition

There is no generally accepted gold standard method for the diagnosis of undernutrition in older people. The Mini Nutritional Assessment (MNA) [30], the Malnutrition Universal Screening Tool [70], and the Subjective Global Assessment $[18,31,73]$ are commonly used diagnosis tools. The most common screening tools are questions about weight loss and the body mass index (BMI), calculated as the weight in kilograms divided by height in meters squared. Appetite reduction usually precedes weight loss. The Simplified Nutritional Appetite Questionnaire comprises four questions on appetite, timing of eating, and frequency of meals and taste and has a high sensitivity and specificity (both $>75 \%$ ) in predicting future $5 \%$ weight loss in older people [91]. The use of this tool in otherwise healthy older people can identify those who require assessment to prevent weight loss. A detailed and further assessment by clinicians usually involves a combination of the following: anthropometric measures, questions regarding weight loss, food intake assessment, medication history, and measurement of blood parameters such as serum albumin, hematocrit, lymphocyte count, total cholesterol, and serum folate (all of which tend to be reduced in malnutrition) $[26,83]$.

\section{Prevalence of undernutrition in the old}

Because there were multiple methods of assessing nutrition and undernutrition, the relevance figures for undernutrition among older people are significantly different. None of the assessing methods have been universally accepted. To enable comparisons across different settings, prevalence figures in this review were based on widely used MNA. The reported prevalence of nutritional risk in older people is approximately $45 \%$ in the community, 45 to $51 \%$ in domiciliary care settings, 50 to $82 \%$ in hospitals, and between 84 and $100 \%$ in residential care facilities [12, 17, 77-79].

Adverse effects of undernutrition

Undernutrition in older people is associated with multiple adverse health consequences, including impaired muscle function, decreased bone mass, immune dysfunction, anemia, reduced cognitive function, poor wound healing, delayed recovery from surgery, and ultimately increased mortality [14]. Beck et al. demonstrated that subjects with better MNA scores (MNA $\geq 24$ ) had significantly lower mortality (odds ratio $0.35,95 \% \mathrm{CI} 0.18-0.66$ ) than subjects at nutritional risk (MNA <24) [6]. Older people often perceive entry into residential care as a bad outcome; individuals are at significant risk of this following an acute illness. Acute illness (inflammation) and prolonged bed rest results in increased protein catabolism, muscle loss, and loss of physical function. Heiat et al. investigated 908 community-dwelling elderly hospitalized patients and demonstrated that elderly malnourished subjects were three times more likely than nourished subjects to be subsequently institutionalized (20.3\% MNA $<17$ vs $7.7 \%$ MNA $\geq 24, P<.001)$ [33]. Visvanathan et al. also demonstrated that undernourished (MNA $<24$ ) community-dwelling older people in receipt of domiciliary care services were more likely to be hospitalized and spend longer in hospital than their nourished counterparts [84].

\section{Management of undernutrition}

When an older person presents with weight loss (particularly $>5 \%$ ) or low BMI (particularly $<20 \mathrm{~kg} / \mathrm{m}^{2}$ ), there is a need to complete a comprehensive assessment and address the nonphysiologic factors. Often, these are not addressed and therefore no improvement is noted. Depression, in particular, is a common cause of undernutrition in the elderly. A person with depression manifesting as weight loss is unlikely to respond well to the provision of nutritional supplements only, as this does not address the loss of appetite, lack of motivation, and lack of energy usually accompanying the depression. After treating, depression is likely to result in increased oral intake and increased willingness to participate in an exercise and nutrition program [83].

Oral nutritional supplements such as high-energy drinks may be beneficial, and it has been recommended that they are taken between meals. In undernourished older people, oral nutritional supplementation has been shown by metaanalysis of controlled trials to produce weight gain, to be free of side effects, and to reduce mortality by up to $34 \%$ among patients in short-term hospital care [41]. Although there is no evidence to support this recommendation, there is a general belief that multivitamin supplements are beneficial in older people and they are unlikely to do harm. Calcium and vitamin D intake should be optimized. Given the changes in appetite and satiety, it has also been suggested that snacking during the day may be beneficial $[1,83]$.

The evidence supporting any pharmacologic agent for the treatment of weight loss is limited [1]. Medications trialed to date, such as megesterol acetate, dronabinol, and human recombinant growth hormone have serious side effects especially in frail older people in whom weight loss is commonly seen and therefore cannot be recommended for routine clinical use at this stage. 


\section{Weight loss of aging}

Weight loss is common in older people. It is associated with increased morbidity and mortality, particularly when unintentional, excessive ( $>5 \%$ body weight), or associated with low body weight (body mass index $<22 \mathrm{~kg} / \mathrm{m}^{2}$ ). Loss of body weight or skeletal muscle mass in older persons can result from voluntary or involuntary causes. Three primary categories of skeletal muscle loss include starvation, sarcopenia, and cachexia [76]. Starvation is a pure protein-energy deficiency, thus forcing a reduction in both fat and fat-free mass. The key physiological sign of starvation is that it is reversed solely by the replenishment of nutrients. Observed age-related decline in muscle mass has been termed sarcopenia. Severe wasting of both fat and fat-free mass is termed cachexia. Cachexia is widely recognized as severe wasting accompanying disease states such as cancer or immunodeficiency disease but does not have a widely accepted definition. We will discuss sarcopenia and cachexia in the latter part of this review. It is often unrecognized, the associated adverse effects not appreciated, and underlying causes not addressed. Intentional weight loss by overweight older people is probably appropriate only when functional problems have resulted from the excess weight. It is important to include, wherever possible, exercise in weightloss measures to preserve skeletal muscle mass [13].

\section{Changes in body weight}

On average, people in developed countries gain weight until they are about 50 to 60 years old, stay fairly weight stable for a while, and then lose weight [81]. Many studies have reported weight loss in elderly people [64]. Stevens et al. demonstrated that women older than 85 years had BMIs $1.8 \mathrm{~kg} / \mathrm{m}^{2}$ less than women aged 55 to 64 years and that men older than 85 years had BMIs $2.6 \mathrm{~kg} / \mathrm{m}^{2}$ lower than men aged 45 to 64 years, corresponding to body weights approximately $4.0 \mathrm{~kg}(9 \mathrm{lb})$ and $5.5 \mathrm{~kg}(12 \mathrm{lb})$ lower in the older adults than the young women and men, respectively [69]. Wallace et al. demonstrated that community-dwelling men older than 65 years lost on average $0.5 \%$ of their body weight per year [85]. As a result of this weight loss and the premature death of obese people at younger ages, the prevalence of overweight and obesity as defined by standard criteria peaks around 55 to 65 years of age and decreases after about 70 to 75 years of age [13]. Schoenborn et al. demonstrated that four times as many people aged 75 years and older than those aged 45 to 64 years were underweight (BMI $<18.5,5.0$ vs $1.2 \%$ ) and substantially fewer were overweight (BMI $>25,47.2$ vs $63.5 \%$ ) [64].

Adverse effects of weight loss in the old

Weight loss among the elderly is often associated with adverse effects, particularly if the weight loss is unintentional. Ideal weight ranges for survival are higher in older adults than in young adults. Undernutrition, most obviously manifesting as both low body weight and weight loss, is common in older people and is associated with significant adverse effects.

Numerous studies have shown that weight loss in the elderly is associated with reduced survival, certainly if the weight loss is involuntary but possibly even when deliberate. A study of Newman et al. demonstrated that subjects older than 65 years, those who lost $5 \%$ or more of their initial body weight in the 3 years after study entry, had twice the death rate over the following 4 years compared with the stable-weight group. Mortality was increased with weight loss regardless of starting weight and whether or not the weight loss was intentional [50]. Somes et al. demonstrated that those who lost $1.6 \mathrm{~kg}$ per year or more weight had a 4.9 times greater death rate than those without significant weight change. The adverse association of weight loss with mortality was present even in the subjects who were heaviest at baseline and was independent of baseline weight [67]. Not surprisingly, unintentional weight loss in older people is associated with more adverse effects than intentional weight loss. Some studies demonstrated increased mortality even after intentional weight loss in older people; it is difficult to determine what proportion of weight loss labeled intentional was instead unintentional [50]. Harrington et al. analyzed 26 studies examining the connection between weight loss and mortality and demonstrated that weight loss that was unintentional or ill defined was associated with a significant (22-39 \%) increase in mortality, whereas intentional weight loss had no significant effect on mortality [32].

An important question is whether the increased death rate in older people who lose weight is caused by the weight loss itself or whether the weight loss is merely a marker of underlying conditions that increase mortality. It is often difficult to know, and both are likely to be true to varying degrees in different people. In some cases, weight loss is caused by an illness, such as a malignancy, that is mainly responsible for the reduced survival and the weight loss is partly an innocent bystander. There are numerous causes of pathologic anorexia and weight loss in older people. Nevertheless, the older person or their caregivers do not often appreciate the weight loss, and when it is appreciated, it can trigger a search for underlying, often treatable, causes. The weight loss and associated undernutrition is itself often a significant problem because weight lost in older persons is disproportionately composed of lean tissue, with its associated adverse effects. Consistent with this, a reduction of mortality has been described in some groups of older people receiving nutritional supplements [13].

Management of weight loss

Evidence suggests that weight loss is typically multifactorial. Three common problems include starvation (or wasting), 
cachexia, and sarcopenia. It is important to identify, plan, and implement actions to correct the causes [52]. An interdisciplinary approach may prove beneficial in preventing weight loss [21]. This approach includes two approaches. The first one is adequate nutrition: the intake of nutrition supplements is a primary intervention [28]. Varieties of supplements are available and provide residents with additional calories and protein. Fortification of foods may be the most suitable way to increase the micronutrient intake of long-term care residents [20]. Fortifying foods allows residents to consume more nutrients without having to increase the volume of food eaten. The second one is feeding assistance: improvement in the quality and adequacy of feeding assistance for mealtimes and snacks has been shown to improve long-term care residents' daily caloric intake and promote weight gain [66]. Use of verbal prompting and social interactions to assist residents to eat better is learned skills. There is little reported experience with weight-loss drugs in older people. The lipase inhibitor orlistat appears to be as effective in older adults but can cause gastrointestinal side effects [81].

\section{Sarcopenia of aging}

Sarcopenia has become a core concept for understanding the necessary course of action to maintain good function at old age. Muscle accounts for about 40 and $75 \%$ of body mass and body cell mass, respectively [49]. Twenty years ago, sarcopenia was defined as the decline in muscle mass and function. Sarcopenia has been most recently defined as "the ageassociated loss of skeletal muscle mass, which results in decreased strength and aerobic capacity and thus functional capacity" [25]. The prevalence of sarcopenia studied in various research studies varies significantly. Within the existing literature, the prevalence of sarcopenia in 60 to 70 years old is in the range of 5 to $13 \%$ [44]. These prevalence estimates increase to 11 to $50 \%$ for the population aged 80 years or older [44].

\section{Influence of sarcopenia on physical function}

Some studies have related sarcopenia to measures of functional status, such as mobility performance, self-reported functional limitations, and disability [4, 93]. Sarcopenia is frequently mentioned as an important risk factor for falls in older persons. The results of two studies are presented next, although in both studies, the fall data were collected retrospectively; at the time of the muscle mass assessment, the falls that occurred in the previous 12 months were reported. Baumgartner et al. studied the relationship of sarcopenia and falls in the past year and reported that $22 \%$ of the men and $31 \%$ of the women reported a fall in the past year [4]. Szulc and his colleagues also studied the relationship between muscle mass and falls. Seven hundred ninety-six men aged 50-85 years were included into the study.
They reported that relative appendicular muscle mass was related to self-reported falls in the past year; $25.4 \%$ men reported a fall in the past year [71].

Some studies investigated the association between low muscle mass and mortality; 1,396 men and women aged 70 years and older were included in this study. The study showed that after adjustment for baseline age, gender, marital status, smoking, self-rated health, ability to conduct activities of daily living, comorbidity, cognition performance, and presence of depression, low arm muscle area was associated with an 8-year mortality risk (hazard ratio (HR) 1.95, $95 \% \mathrm{CI}$ 1.25-2.00) [40]. Enoki et al. reported the relationship between arm muscle area (square centimeter) and mortality. In multivariate analyses, adjusting for age, gender, functional status, comorbidity status, and triceps skinfold thickness as a measure of body fatness, low arm muscle area was associated with a higher mortality risk (HR 2.03, 95 \% CI 1.36-3.02) compared with high arm muscle area [22].

\section{Pharmacologic treatment of sarcopenia}

Sarcopenia is a complex multifactorial condition that can by treated with multimodal methods. No pharmacologic medicine to prevent or treat sarcopenia has proven to be as efficacious as exercise (mainly resistance training) in combination with nutritional intervention (adequate protein and energy intake). This approach is currently the key strategy for the management of sarcopenia [45]. Some new pharmacologic medicines may radically transfer the therapeutic method to sarcopenia.

Testosterone levels gradually decline in elderly men at a rate of $1 \%$ per year. Some studies reported the relationship between low levels of testosterone in elderly men and loss of muscle mass, strength, and function [53]. Currently, supraphysiologic doses of testosterone are known to dramatically increase muscle mass and strength in young subjects performing resistance training. In hypogonadal elderly men, testosterone administration increased muscle mass and muscle strength, decreased fat mass, and has been reported to improve rehabilitation outcomes [36].

Growth hormone $(\mathrm{GH})$ promotes muscle growth through favoring the maturation of muscle satellite cells. It also induces an increase in muscular oxidative enzymes and fatigue resistance through improving muscle mitochondrial functioning [60]. However, conflicting results have been reported during GH supplementation in older people with somatopause [72]. Other medications, which can also treat the sarcopenia, include lepin [61], vitamin D [9], myostatin [56], and so on.

Physical therapy of sarcopenia

In considering physical training strategies for sarcopenic subjects, physical activity can be a valuable countermeasure 
to sarcopenia in its treatment and prevention. Some studies suggested that sarcopenia may be secondary to muscle weakness in the elderly and demonstrated that muscle strength, but not muscle mass, is independently associated with lower extremity performance, another factor for disability among older persons [82]. Experimental and epidemiologic data have established that physical activity is useful for the primary and tertiary preventions of sarcopenia. It is therefore critical to provide subjects with guidelines to ensure safe and effective practice, just as for drug prescription. Exercise is a medicine for chronic disease, and physicians need to prescribe exercise in the same manner as they prescribe drugs [62]. Individual or collective, indoor or outdoor, with or without a technical support, aquatic or not - these are the defining characteristics of physical activity. Exercise intensity can be defined using subjective indicators such as a scoring scale [54].

\section{Cachexia of aging}

Cachexia has long been recognized as a syndrome associated with many illnesses. However, the underlying mechanisms causing cachexia are not well understood and there is no universally agreed upon definition. Up to now, the generally accepted cachexia definition is that it is a complex metabolic syndrome associated with underlying illness and characterized by loss of muscle with or without loss of fat mass. The prominent clinical feature of cachexia is weight loss in adults (corrected for fluid retention) or growth failure in children (excluding endocrine disorders). Anorexia, inflammation, insulin resistance, and increased muscle protein breakdown are frequently associated with wasting disease. Wasting disease is distinct from starvation, age-related loss of muscle mass, primary depression, malabsorption, and hyperthyroidism and is associated with increased morbidity [23].

Cachexia is not a simple weight loss but is a complex condition involving wasting of skeletal muscle associated with anemia, lipolysis, insulin resistance, anorexia, and sickness syndrome. Specific disease states are frequently associated with cachexia. Persons with cachexia due to cancer may deplete up to $80 \%$ of their muscle mass [67] More than $80 \%$ of persons with upper gastrointestinal cancer have cachexia at diagnosis, and more than $60 \%$ of lung cancer patients develop cachexia. HIV/AIDS [59], rheumatoid arthritis [5], chronic renal insufficiency, chronic uremia [10], and elderly persons without obvious cause [23] have been associated with cachexia.

Cachexia is often associated with cytokine excess. Proinflammatory cytokines have been found in apparently healthy older persons as a function of age. Age greater than 70 years is associated with increased circulating plasma levels of interleukin-6 (IL-6) independent of disease states and disorders of aging [15]. The difference in levels of IL-6 in randomly selected older persons compared with strictly selected healthy older persons suggests that inflammatory activity may be a marker of health status [2]. Increased levels of circulating inflammatory components including tumor necrosis factor-alpha, IL-6, IL-1 receptor antagonist, soluble tumor necrosis factor receptor, C-reactive protein, serum amyloid $\mathrm{A}$, and high neutrophil counts have been observed in older adults. These age-related changes in immune function are associated with progressively increased levels of glucocorticoids and catecholamines and decreased growth and sex hormones, a pattern reminiscent of that seen in chronic stress [23].

\section{Diagnosis of cachexia}

The consensus panel developed a set of diagnostic criteria to allow clinicians and researchers to make a definitive diagnosis of cachexia. The key component was at least a $5 \%$ loss of edema-free body weight during the previous 12 months or less. The time frame may be disease specific and is likely to be shorter in cancer (3-6 months) and longer in chronic kidney or heart failure or COPD (12 months). In cases where a history of weight loss cannot be documented, a BMI of $<20.0 \mathrm{~kg} / \mathrm{m}^{2}$ was considered sufficient to establish a diagnosis of cachexia. Other diagnostic criteria for cachexia besides loss of muscle mass or evidence of accelerated protein degradation in muscle are decreased muscle strength, fatigue, anorexia, low muscle (fat-free) mass, and biochemical abnormalities characteristic of inflammation, anemia, or hypoalbuminemia. Ewans et al. believe that staging of cachexia is possible and will prove useful. For future research, Ewan et al. suggest classifying the degree of cachexia as mild, moderate, or severe, depending on whether the observed weight loss within the previous 12 months (or less) is $>5,>10$, or $>15$, respectively [23].

\section{Treatment of cachexia}

The treatment options for cachexia are limited. Unfortunately, refeeding a patient with cachexia does not correct the underlying problem. Even with total parenteral nutrition, weight stabilization does not prevent the continuing loss of skeletal muscle mass or correct the underlying abnormality in the metabolic state. Potential strategies for treating cachexia target skeletal muscle wasting in the presence of adequate nutrition [48]. In contrast to starvation, cachexia is remarkably resistant to hypercaloric feeding. Pharmacological treatment of anorexia with agents that modulate cytokine production may produce weight gain in cachexia states [75]. Steroids and hormonal agents such as megesterol acetate are currently widely used in the treatment of cachexia and anorexia [19]. These drugs act through multiple 
pathways, such as increasing neuropeptide-Y levels to increase appetite and downregulating proinflammatory cytokines. Thalidomide significantly attenuated both total weight loss and loss of lean body mass in patients with cancer and acquired immunodeficiency syndrome [27]. Eicosapentaenoic acid can halt weight loss in cancer cachexia and may increase lean body mass at high doses [24]. The results of these pharmacological trials suggest that improvement in cachexia results from a common effect of these agents on proinflammatory cytokines.

\section{Conclusion}

Anorexia, undernutrition, weight loss, sarcopenia, and cachexia in older people are very common. These issues may be five different stages of one process. These conditions associated with numerous adverse consequences and increased morbidity and mortality, especially in undernourished and weigh loss patients. These important health issues are frequently overlooked. Clinical physician should enhance the recognition of anorexia, undernutrition, weight loss, sarcopenia, and cachexia. We recommended that these patients should take a timely, adequate, comprehensive assessment and adopt measures to enable restoration of muscle mass and strength.

\section{References}

1. Alibhai SM, Greenwood C, Payette H (2005) An approach to the management of unintentional weight loss in elderly people. CMAJ 172:773-780

2. Baggio G, Donazzan S, Monti D, Mari D, Martini S, Gabelli C, Dalla Vestra M, Previato L, Guido M, Pigozzo S, Cortella I, Crepaldi G, Franceschi C (1998) Lipoprotein(a) and lipoprotein profile in healthy centenarians: a reappraisal of vascular risk factors. FASEB J 12:433437

3. Balducci L (2010) Anemia, fatigue and aging. Transfus Clin Biol 17:375-381

4. Baumgartner RN, Koehler KM, Gallagher D, Romero L, Heymsfield SB, Ross RR, Garry PJ, Lindeman RD (1998) Epidemiology of sarcopenia among the elderly in New Mexico. Am J Epidemiol 147:755-763

5. Bearne LM, Scott DL, Hurley MV (2002) Exercise can reverse quadriceps sensorimotor dysfunction that is associated with rheumatoid arthritis without exacerbating disease activity. Rheumatology (Oxford) 41:157-166

6. Beck AM, Ovesen L, Osler M (1999) The 'Mini Nutritional Assessment' (MNA) and the 'Determine Your Nutritional Health' Checklist (NSI Checklist) as predictors of morbidity and mortality in an elderly Danish population. Br J Nutr 81:31-36

7. Biberstine KJ, Rosenthal RS (1994) Peptidoglycan fragments decrease food intake and body weight gain in rats. Infect Immun 62:3276-3281

8. Boyce JM, Shone GR (2006) Effects of ageing on smell and taste. Postgrad Med J 82:239-241
9. Braddy KK, Imam SN, Palla KR, Lee TA (2009) Vitamin D deficiency/insufficiency practice patterns in a veterans health administration long-term care population: a retrospective analysis. $\mathrm{J}$ Am Med Dir Assoc 10:653-657

10. Castaneda C, Gordon PL, Uhlin KL, Levey AS, Kehayias JJ, Dwyer JT, Fielding RA, Roubenoff R, Singh MF (2001) Resistance training to counteract the catabolism of a low-protein diet in patients with chronic renal insufficiency. A randomized, controlled trial. Ann Intern Med 135:965-976

11. Centers for Disease Control (2003) Public Health and Aging: trends in aging-United States and worldwide. MMWR Morb Mortal Wkly Rep 52:101-104, 106

12. Cereda E, Valzolgher L, Pedrolli C (2008) Mini nutritional assessment is a good predictor of functional status in institutionalised elderly at risk of malnutrition. Clin Nutr 27:700-705

13. Chapman IM (2011) Weight loss in older persons. Med Clin North Am 95:579-593, xi

14. Chapman I, Parker B, Doran S, Feinle-Bisset C, Wishart J, Lush CW, Chen K, Lacerte C, Burns C, McKay R, Weyer C, Horowitz M (2007) Low-dose pramlintide reduced food intake and meal duration in healthy, normal-weight subjects. Obesity (Silver Spring) 15:11791186

15. Cohen HJ, Pieper CF, Harris T, Rao KM, Currie MS (1997) The association of plasma IL-6 levels with functional disability in community-dwelling elderly. J Gerontol A Biol Sci Med Sci 52: M201-M208

16. Crimmins E, Vasunilashorn S, Kim JK, Alley D (2008) Biomarkers related to aging in human populations. Adv Clin Chem 46:161-216

17. Cuervo M, Ansorena D, Martinez-Gonzalez MA, Garcia A, Astiasaran I, Martinez JA (2009) Impact of global and subjective mini nutritional assessment (MNA) questions on the evaluation of the nutritional status: the role of gender and age. Arch Gerontol Geriatr 49:69-73

18. de Mutsert R, Grootendorst DC, Boeschoten EW, Brandts H, van Manen JG, Krediet RT, Dekker FW (2009) Subjective global assessment of nutritional status is strongly associated with mortality in chronic dialysis patients. Am J Clin Nutr 89:787-793

19. Deans C, Wigmore SJ (2005) Systemic inflammation, cachexia and prognosis in patients with cancer. Curr Opin Clin Nutr Metab Care 8:265-269

20. Dunne JL, Dahl WJ (2007) A novel solution is needed to correct low nutrient intakes in elderly long-term care residents. Nutr Rev 65:135138

21. Dyck MJ, Schumacher JR (2011) Evidence-based practices for the prevention of weight loss in nursing home residents. J Gerontol Nurs 37:22-33, quiz 34-25

22. Enoki H, Kuzuya M, Masuda Y, Hirakawa Y, Iwata M, Izawa S, Hasegawa J, Iguchi A (2007) Anthropometric measurements as a predictor of mortality of community-dwelling Japanese elderly: the Nagoya Longitudinal Study of Frail Elderly (NLS-FE). Nihon Ronen Igakkai Zasshi 44:212-218

23. Evans WJ, Morley JE, Argiles J, Bales C, Baracos V, Guttridge D, Jatoi A, Kalantar-Zadeh K, Lochs H, Mantovani G, Marks D, Mitch WE, Muscaritoli M, Najand A, Ponikowski P, Rossi Fanelli F, Schambelan M, Schols A, Schuster M, Thomas D, Wolfe R, Anker SD (2008) Cachexia: A new definition. Clin Nutr 27:793799

24. Fearon KC, Von Meyenfeldt MF, Moses AG, Van Geenen R, Roy A, Gouma DJ, Giacosa A, Van Gossum A, Bauer J, Barber MD, Aaronson NK, Voss AC, Tisdale MJ (2003) Effect of a protein and energy dense N-3 fatty acid enriched oral supplement on loss of weight and lean tissue in cancer cachexia: a randomised double blind trial. Gut 52:1479-1486

25. Fielding RA, Vellas B, Evans WJ, Bhasin S, Morley JE, Newman AB, Abellan van Kan G, Andrieu S, Bauer J, Breuille D, Cederholm T, Chandler J, De Meynard C, Donini L, Harris T, Kannt A, Keime 
Guibert F, Onder G, Papanicolaou D, Rolland Y, Rooks D, Sieber C, Souhami E, Verlaan S, Zamboni M (2011) Sarcopenia: an undiagnosed condition in older adults. Current consensus definition: prevalence, etiology, and consequences. International working group on sarcopenia. J Am Med Dir Assoc 12:249-256

26. Fuhrman MP, Charney P, Mueller CM (2004) Hepatic proteins and nutrition assessment. J Am Diet Assoc 104:1258-1264

27. Gordon JN, Trebble TM, Ellis RD, Duncan HD, Johns T, Goggin PM (2005) Thalidomide in the treatment of cancer cachexia: A randomised placebo controlled trial. Gut 54:540-545

28. Gosney M (2003) Are we wasting our money on food supplements in elder care wards? J Adv Nurs 43:275-280

29. Gruenewald TL, Seeman TE, Karlamangla AS, Sarkisian CA (2009) Allostatic load and frailty in older adults. J Am Geriatr Soc 57:1525-1531

30. Guigoz Y, Lauque S, Vellas BJ (2002) Identifying the elderly at risk for malnutrition. The Mini Nutritional Assessment. Clin Geriatr Med 18:737-757

31. Gupta B, Kant S, Mishra R (2010) Subjective global assessment of nutritional status of chronic obstructive pulmonary disease patients on admission. Int J Tuberc Lung Dis 14:500-505

32. Harrington M, Gibson S, Cottrell RC (2009) A review and metaanalysis of the effect of weight loss on all-cause mortality risk. Nutr Res Rev 22:93-108

33. Heiat A, Vaccarino V, Krumholz HM (2001) An evidence-based assessment of federal guidelines for overweight and obesity as they apply to elderly persons. Arch Intern Med 161:1194-1203

34. Jiawiwatkul U, Aekplakorn W, Vapattanawong P, Prasartkul P, Poraphakkham Y (2011) Changes in active life expectancy among older Thais: results from the 1997 and 2004 National Health Examination Surveys. Asia Pac J Public Health

35. Koehler KM (1994) The New Mexico aging process study. Nutr Rev 52:S34-S37

36. Ly LP, Jimenez M, Zhuang TN, Celermajer DS, Conway AJ, Handelsman DJ (2001) A double-blind, placebo-controlled, randomized clinical trial of transdermal dihydrotestosterone gel on muscular strength, mobility, and quality of life in older men with partial androgen deficiency. J Clin Endocrinol Metab 86:4078-4088

37. MacIntosh CG, Andrews JM, Jones KL, Wishart JM, Morris HA, Jansen JB, Morley JE, Horowitz M, Chapman IM (1999) Effects of age on concentrations of plasma cholecystokinin, glucagon-like peptide 1, and peptide YY and their relation to appetite and pyloric motility. Am J Clin Nutr 69:999-1006

38. Maggio M, Guralnik JM, Longo DL, Ferrucci L (2006) Interleukin-6 in aging and chronic disease: a magnificent pathway. J Gerontol A Biol Sci Med Sci 61:575-584

39. Matsuda T, Doty RL (1995) Regional taste sensitivity to $\mathrm{NaCl}$ : Relationship to subject age, tongue locus and area of stimulation. Chem Senses 20:283-290

40. Miller MD, Crotty M, Giles LC, Bannerman E, Whitehead C, Cobiac L, Daniels LA, Andrews G (2002) Corrected arm muscle area: An independent predictor of long-term mortality in community-dwelling older adults? J Am Geriatr Soc 50:1272-1277

41. Milne AC, Avenell A, Potter J (2006) Meta-analysis: protein and energy supplementation in older people. Ann Intern Med 144:3748

42. Morley JE (1997) Anorexia of aging: Physiologic and pathologic. Am J Clin Nutr 66:760-773

43. Morley JE (2007) The aging gut: Physiology. Clin Geriatr Med 23:757-767, v-vi

44. Morley JE (2008) Sarcopenia: diagnosis and treatment. J Nutr Health Aging 12:452-456

45. Morley JE, Argiles JM, Evans WJ, Bhasin S, Cella D, Deutz NE, Doehner W, Fearon KC, Ferrucci L, Hellerstein MK, Kalantar-Zadeh K, Lochs H, MacDonald N, Mulligan K, Muscaritoli M, Ponikowski P, Posthauer ME, Rossi Fanelli F, Schambelan M, Schols AM,
Schuster MW, Anker SD (2010) Nutritional recommendations for the management of sarcopenia. J Am Med Dir Assoc 11:391-396

46. Morley JE, Kumar VB, Mattammal MB, Farr S, Morley PM, Flood JF (1996) Inhibition of feeding by a nitric oxide synthase inhibitor: Effects of aging. Eur J Pharmacol 311:15-19

47. Morley JE, Silver AJ, Miller DK, Rubenstein LZ (1989) The anorexia of the elderly. Ann N Y Acad Sci 575:50-58, discussion $58-59$

48. Morley JE, Thomas DR, Wilson MM (2006) Cachexia: pathophysiology and clinical relevance. Am J Clin Nutr 83:735-743

49. Nair KS (2000) Age-related changes in muscle. Mayo Clin Proc 75 (Suppl):S14-S18

50. Newman AB, Yanez D, Harris T, Duxbury A, Enright PL, Fried LP (2001) Weight change in old age and its association with mortality. J Am Geriatr Soc 49:1309-1318

51. Ooyama K, Kojima K, Aoyama T, Takeuchi H (2009) Decrease of food intake in rats after ingestion of medium-chain triacylglycerol. J Nutr Sci Vitaminol (Tokyo) 55:423-427

52. Pedersen PU (2005) Nutritional care: The effectiveness of actively involving older patients. J Clin Nurs 14:247-255

53. Perry HM 3rd, Miller DK, Patrick P, Morley JE (2000) Testosterone and leptin in older African-American men: Relationship to age, strength, function, and season. Metabolism 49:1085-1091

54. Pillard F, Laoudj-Chenivesse D, Carnac G, Mercier J, Rami J, Riviere D, Rolland Y (2011) Physical activity and sarcopenia. Clin Geriatr Med 27:449-470

55. Riediger T, Cordani C, Potes CS, Lutz TA (2010) Involvement of nitric oxide in lipopolysaccharide induced anorexia. Pharmacol Biochem Behav 97:112-120

56. Rodino-Klapac LR, Haidet AM, Kota J, Handy C, Kaspar BK, Mendell JR (2009) Inhibition of myostatin with emphasis on follistatin as a therapy for muscle disease. Muscle Nerve 39:283-296

57. Rodrigues Pereira N, Bandeira Moss M, Assumpcao CR, Cardoso CB, Mann GE, Brunini TM, Mendes-Ribeiro AC (2010) Oxidative stress, 1-arginine-nitric oxide and arginase pathways in platelets from adolescents with anorexia nervosa. Blood Cells Mol Dis 44:164-168

58. Rolland Y, Kim MJ, Gammack JK, Wilson MM, Thomas DR, Morley JE (2006) Office management of weight loss in older persons. Am J Med 119:1019-1026

59. Roubenoff R, Wilson IB (2001) Effect of resistance training on selfreported physical functioning in HIV infection. Med Sci Sports Exerc 33:1811-1817

60. Rudman D, Kutner MH, Rogers CM, Lubin MF, Fleming GA, Bain RP (1981) Impaired growth hormone secretion in the adult population: relation to age and adiposity. J Clin Invest 67:1361-1369

61. Sainz N, Rodriguez A, Catalan V, Becerril S, Ramirez B, GomezAmbrosi J, Fruhbeck G (2009) Leptin administration favors muscle mass accretion by decreasing FoxO3a and increasing PGC-1alpha in ob/ob mice. PLoS One 4:e6808

62. Sallis RE (2009) Exercise is medicine and physicians need to prescribe it! Br J Sports Med 43:3-4

63. Schiffman SS (1991) Taste and smell losses with age. Bol Asoc Med P R 83:411-414

64. Schoenborn CA, Adams PF, Barnes PM (2002) Body weight status of adults: United States, 1997-98, Adv Data, 1-15.

65. Sih R, Morley JE, Kaiser FE, Perry HM 3rd, Patrick P, Ross C (1997) Testosterone replacement in older hypogonadal men: A 12-month randomized controlled trial. J Clin Endocrinol Metab 82:1661-1667

66. Simmons SF, Garcia ET, Cadogan MP, Al-Samarrai NR, LevyStorms LF, Osterweil D, Schnelle JF (2003) The minimum data set weight-loss quality indicator: Does it reflect differences in care processes related to weight loss? J Am Geriatr Soc 51:1410-1418

67. Somes GW, Kritchevsky SB, Shorr RI, Pahor M, Applegate WB (2002) Body mass index, weight change, and death in older adults: The systolic hypertension in the elderly program. Am J Epidemiol 156:132-138 
68. Squadrito F, Calapai G, Altavilla D, Cucinotta D, Zingarelli B, Arcoraci V, Campo GM, Caputi AP (1994) Central serotoninergic system involvement in the anorexia induced by NG-nitro-L-arginine, an inhibitor of nitric oxide synthase. Eur J Pharmacol 255:51-55

69. Stevens J, Cai J, Pamuk ER, Williamson DF, Thun MJ, Wood JL (1998) The effect of age on the association between body-mass index and mortality. N Engl J Med 338:1-7

70. Stratton RJ, King CL, Stroud MA, Jackson AA, Elia M (2006) 'Malnutrition Universal Screening Tool' predicts mortality and length of hospital stay in acutely ill elderly. Br J Nutr 95:325-330

71. Szulc P, Beck TJ, Marchand F, Delmas PD (2005) Low skeletal muscle mass is associated with poor structural parameters of bone and impaired balance in elderly men - the MINOS study. J Bone Miner Res 20:721-729

72. Taaffe DR, Pruitt L, Reim J, Hintz RL, Butterfield G, Hoffman AR, Marcus R (1994) Effect of recombinant human growth hormone on the muscle strength response to resistance exercise in elderly men. $\mathrm{J}$ Clin Endocrinol Metab 79:1361-1366

73. Taniguchi E, Kawaguchi T, Itou M, Oriishi T, Ibi R, Torii M, Yoshida K, Adachi Y, Otsuka M, Uchida Y, Tanaka S, Takakura M, Sata M (2011) Subjective global assessment is not sufficient to screen patients with defective hepatic metabolism. Nutrition 27:282-286

74. Tedla FM, Friedman EA (2008) The trend toward geriatric nephrology. Prim Care 35:515-530, vii

75. Thomas DR (2006) Guidelines for the use of orexigenic drugs in long-term care. Nutr Clin Pract 21:82-87

76. Thomas DR (2007) Loss of skeletal muscle mass in aging: Examining the relationship of starvation, sarcopenia and cachexia. Clin Nutr 26:389-399

77. Tsai AC, Chou YT, Chang TL (2011) Usefulness of the Mini Nutritional Assessment (MNA) in predicting the nutritional status of people with mental disorders in Taiwan. J Clin Nurs 20:341-350

78. Tsai AC, Chou YT, Chang TL, Chang-Lee SN, Tsay SF (2009) A modified Mini Nutritional Assessment without BMI can effectively assess the nutritional status of neuropsychiatric patients. J Clin Nurs 18:1916-1922

79. Tsai AC, Shih CL (2009) A population-specific Mini-Nutritional Assessment can effectively grade the nutritional status of stroke rehabilitation patients in Taiwan. J Clin Nurs 18:82-88

80. Vignini A, Canibus P, Nanetti L, Montecchiani G, Faloia E, Cester AM, Boscaro M, Mazzanti L (2008) Lipoproteins obtained from anorexia nervosa patients induce higher oxidative stress in U373MG astrocytes through nitric oxide production. Neuromolecular Med 10:17-23

81. Villareal DT, Apovian CM, Kushner RF, Klein S (2005) Obesity in older adults: Technical review and position statement of the
American Society for Nutrition and NAASO. The Obesity Society. Am J Clin Nutr 82:923-934

82. Visser M, Newman AB, Nevitt MC, Kritchevsky SB, Stamm EB, Goodpaster BH, Harris TB (2000) Reexamining the sarcopenia hypothesis. Muscle mass versus muscle strength. Health, Aging, and Body Composition Study Research Group. Ann N Y Acad Sci 904:456-461

83. Visvanathan R, Chapman IM (2009) Undernutrition and anorexia in the older person. Gastroenterol Clin North Am 38:393409

84. Visvanathan R, Macintosh C, Callary M, Penhall R, Horowitz M, Chapman I (2003) The nutritional status of 250 older Australian recipients of domiciliary care services and its association with outcomes at 12 months. J Am Geriatr Soc 51:1007-1011

85. Wallace JI, Schwartz RS, LaCroix AZ, Uhlmann RF, Pearlman RA (1995) Involuntary weight loss in older outpatients: incidence and clinical significance. J Am Geriatr Soc 43:329-337

86. Walston J, Hadley EC, Ferrucci L, Guralnik JM, Newman AB, Studenski SA, Ershler WB, Harris T, Fried LP (2006) Research agenda for frailty in older adults: toward a better understanding of physiology and etiology: summary from the American Geriatrics Society/National Institute on Aging Research conference on frailty in older adults. J Am Geriatr Soc 54:991-1001

87. Wansink B, Payne CR (2007) Counting bones: Environmental cues that decrease food intake. Percept Mot Skills 104:273-276

88. Weiffenbach JM, Cowart BJ, Baum BJ (1986) Taste intensity perception in aging. $J$ Gerontol 41:460-468

89. Weiss CO, Boyd CM, Yu Q, Wolff JL, Leff B (2007) Patterns of prevalent major chronic disease among older adults in the United States. JAMA 298:1160-1162

90. Wilson MM, Morley JE (2003) Invited review: Aging and energy balance. J Appl Physiol 95:1728-1736

91. Wilson MM, Thomas DR, Rubenstein LZ, Chibnall JT, Anderson S, Baxi A, Diebold MR, Morley JE (2005) Appetite assessment: Simple appetite questionnaire predicts weight loss in communitydwelling adults and nursing home residents. Am J Clin Nutr 82:1074-1081

92. Wurtman JJ, Lieberman H, Tsay R, Nader T, Chew B (1988) Calorie and nutrient intakes of elderly and young subjects measured under identical conditions. J Gerontol 43:B174B180

93. Zoico E, Di Francesco V, Guralnik JM, Mazzali G, Bortolani A, Guariento S, Sergi G, Bosello O, Zamboni M (2004) Physical disability and muscular strength in relation to obesity and different body composition indexes in a sample of healthy elderly women. Int J Obes Relat Metab Disord 28:234-241 